\title{
Therapeutic interventions and adjustments in the management of Parkinson disease: role of combined carbidopa/levodopa/entacapone $\left(\right.$ Stalevo $\left.{ }^{\circledR}\right)$
}

\author{
This article was published in the following Dove Press journal: \\ Neuropsychiatric Disease and Treatment \\ 29 July 2010 \\ Number of times this article has been viewed
}

Paolo Solla

Antonino Cannas

Francesco Marrosu

Maria Giovanna Marrosu

Movement Disorders Center, Institute of Neurology, University of Cagliari, Cagliari, Italy
Correspondence: Paolo Solla Movement Disorders Center, Institute of Neurology, University of Cagliari, Via Ospedale 4609I24, Cagliari, Italy

Tel +39-347-90I7706

Fax +39-070-668664

Email paosol29@yahoo.it

\begin{abstract}
Parkinson disease (PD) is a neurodegenerative disorder characterized by 3 cardinal motor symptoms: resting tremor, rigidity, and bradykinesia. Since its introduction 40 years ago, levodopa has represented the gold standard for dopaminergic stimulation therapy in patients with PD. Levodopa is routinely combined with a dopa-decarboxylase inhibitor (DDCI) to prevent the conversion of levodopa into dopamine in peripheral circulation. However, up to $80 \%$ of patients treated with continuous levodopa manifest the onset of disabling motor complications capable of producing an adverse effect on quality of life as the disease progresses. In recent years, a new, safe, and efficacious armamentarium of treatment options has been provided by the marketing of the catechol-O-methyltransferase (COMT) inhibitor, entacapone, a peripheral blocker of dopa to 3-0-methyldopa metabolism, which increments levodopa brain availability. When administered with levodopa, entacapone conjugates the rapid onset of levodopa-induced effects with a protracted efficiency, thus providing additional benefits to classic levodopa treatment by increasing "on" time in fluctuating PD patients, and theoretically providing a more continuous and physiological-like stimulation of dopamine receptors implying a reduced risk of motor complications. In this context, the use of a single administration of combined carbidopa/levodopa/entacapone (Stalevo ${ }^{\circledR}$ ) in the treatment of PD affords clinical improvements similar to those obtained by 2 separate tablets (ie, levodopa/DDCI and entacapone), although the former produces a more positive effect on quality of life than the latter. Additionally, the STalevo Reduction In Dyskinesia Evaluation (STRIDE-PD) study was designed with the aim of demonstrating that the combination of levodopa, carbidopa, and entacapone, used as initial levodopa therapy, significantly delays the onset of dyskinesias compared with the conventional levodopa/carbidopa formulation. Unfortunately, STRIDEPD failed to prove the benefit of continuous dopaminergic stimulation with triple therapy in a clinical setting. Recently, the effect of combined COMT inhibitor with levodopa administration in reducing homocysteine synthesis has been described. To this regard, clear evidence has been presented indicating homocysteine as a risk factor for vascular diseases, cognitive impairment, and dementia. Several studies have discussed the potential of entacapone as adjunct to levodopa/ DDCI in reducing plasma homocysteine levels with contrasting results.

Keywords: Parkinson disease, carbidopa/levodopa/entacapone
\end{abstract}

\section{Introduction}

Parkinson disease (PD) is a neurodegenerative disorder characterized by 3 cardinal motor symptoms: resting tremor, rigidity, and bradykinesia, ${ }^{1}$ affecting approximately $1 \%$ of subjects older than 60 years and representing the second most common neurodegenerative disorder (after Alzheimer disease) in this population. ${ }^{2,3}$ 
Since its introduction 40 years ago, levodopa has constituted the most efficacious and well-tolerated symptomatic treatment for dopaminergic stimulation therapy in patients with PD. ${ }^{4}$

Levodopa is routinely combined with a dopa-decarboxylase inhibitor (DDCI; Figure 1), either carbidopa $\left(\right.$ Sinemet $\left.^{\circledR}\right)$ or benserazide (Madopar $\left.{ }^{\circledR}\right)$, to prevent the conversion of levodopa into dopamine in the peripheral circulation, thereby allowing a greater quantity of levodopa to reach the brain after active transport across the blood-brain barrier. ${ }^{5}$ However, as the disease progresses, up to $80 \%$ of patients who continued to receive levodopa treatment experience the onset of disabling motor complications, such as "wearing-off" symptoms, dyskinesias, and "on-off" mobility patterns. ${ }^{6}$ Approximately $10 \%$ of PD patients per year develop motor complications after starting levodopa treatment, which increases to almost $100 \%$ of patients after 10 years of levodopa therapy. ${ }^{7.8} \mathrm{~A}$ retrospective analysis of the CALM-PD (Comparison of the agonist pramipexole with levodopa on motor complications of Parkinson's disease) study estimated an incidence of motor fluctuations within a range of $12 \%-60 \%$ and an incidence of dyskinesias from $8 \%$ to $64 \%$ after 4-6 years of levodopa treatment. ${ }^{9}$ Although the pathogenesis of these motor fluctuations is not completely understood, these effects are presumably related to the short half-life of levodopa, perhaps as a function of a nonphysiological, pulsatile stimulation of dopamine receptors. ${ }^{10-12}$ These complications may become severely disabling, producing a profound effect on patients' and caregivers' quality of life and representing a major challenge in the long-term treatment of patients with PD. In order to delay or prevent levodopa-induced complications, several therapeutic strategies are commonly used to manage these symptoms, ${ }^{13}$ providing cumulating evidence that continuous nigrostriatal postsynaptic dopaminergic receptor stimulation may prevent the onset of these complications. ${ }^{14}$

\section{Drugs used in the management of motor complications}

Many parkinsonologists recommend dopamine agonist (DA) drugs, such as bromocriptine, pergolide, cabergoline, lisuride, apomorphine, pramipexole, ropinirole, and rotigotine, as initial dopaminergic therapy, ${ }^{15}$ with the aim of improving motor response and decreasing "off" time, supposedly through direct stimulation of dopamine receptors. Based on a consistent body of evidence from randomised controlled trials, the DA drugs dihydroergocryptine, pergolide, pramipexole, ropinirole, and rotigotine, used as monotherapy, have all been shown to be an effective symptomatic treatment in the early stages of PD, ${ }^{16-20}$ delaying the introduction of levodopa by several months or years. ${ }^{21}$ Moreover, PD patients treated with DAs including pergolide, ${ }^{22}$ cabergoline, ${ }^{23}$ pramipexole,,$^{24,25}$ and ropinirole ${ }^{26}$ have been compared with patients treated with levodopa in large, double-blind, randomized trials, revealing a significantly reduced risk of motor complications, such as dyskinesias over

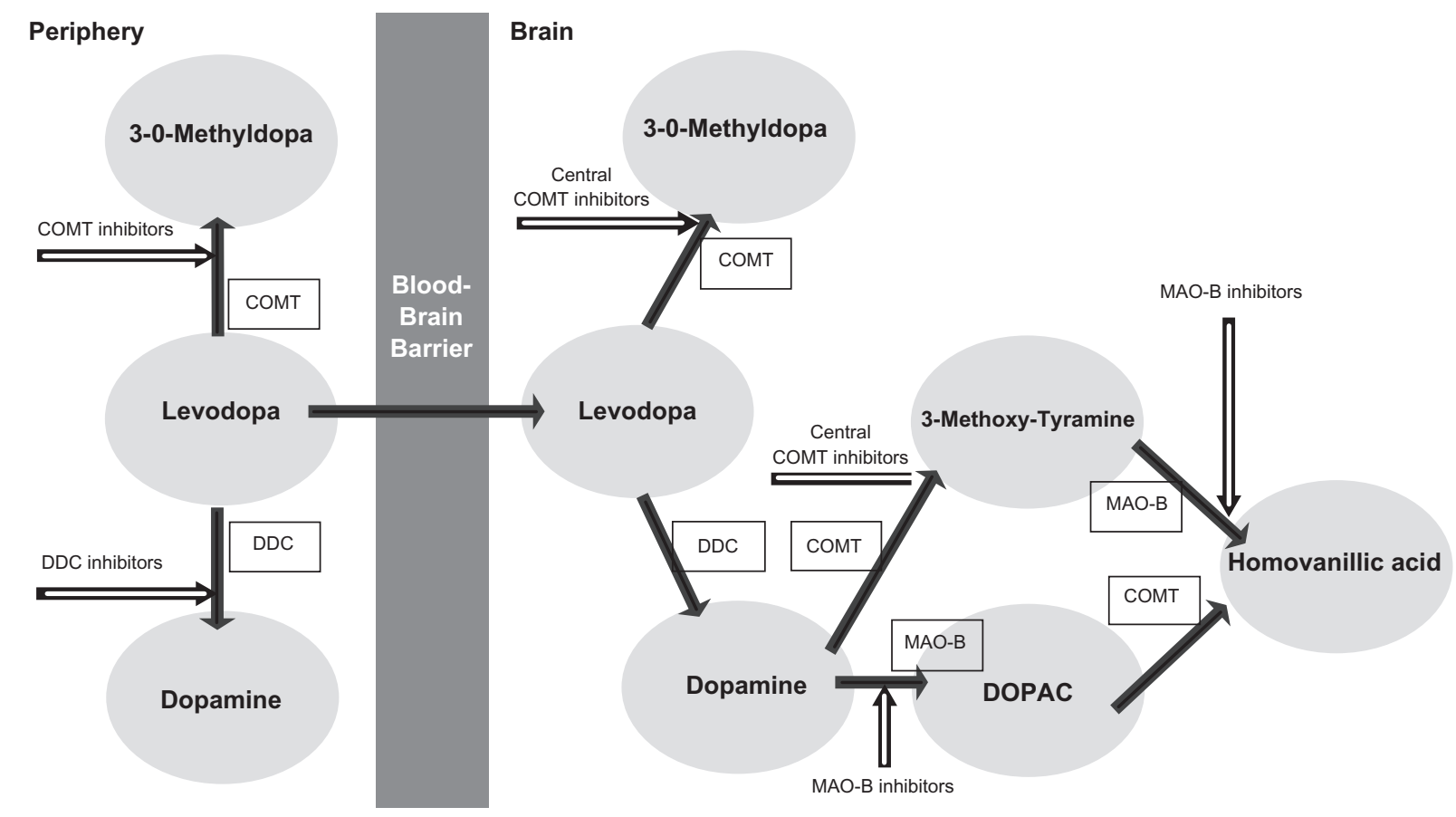

Figure I Metabolic pathways of levodopa.

Abbreviations: COMT, catechol-O-methyltransferase; DDC, dopa-decarboxylase; DOPAC, 3,4-dihydroxyphenylacetic acid; MAO-B, monoamine oxidase type B. 
follow-up periods of up to 5 years. Indeed, DAs are also used as first-line drugs in adjunct therapy in patients treated with levodopa presenting motor fluctuations. The efficacy of DAs in reducing motor complications is believed to be a result of their long half-lives, leading to increasingly constant plasma concentrations and hence a reduction in pulsatile striatal dopamine receptor stimulation. On the basis of preclinical studies highlighting the potential neuroprotective activity of DAs, these drugs have been investigated for their putative diseasemodifying effects. To this regard, 2 double-blind randomized trials, ${ }^{27,28}$ with in vivo imaging using either F-dopa/positron emission tomography (PET) or $\beta$-CIT/single photon emission computed tomography (SPECT), have been performed to evaluate the progressive loss of dopaminergic neurons in patients with early PD. These 2 imaging studies, using ropinirole (REAL-PET) and pramipexole (CALM-PD CIT), have demonstrated that treatment with DAs was associated with a significant decrease in the rate of decline of putaminal F-dopa or striatal $\beta$-CIT uptake, markers of dopaminergic neuron degeneration, compared with that observed for levodopa. The findings of these trials indicated that treatment with ropinirole and pramipexole, compared with levodopa, may alter the rate of disease progression, although no conclusive findings were provided to determine whether the results reflect a neuroprotective action provided by DAs or an effect of levodopa-induced toxicity. Unfortunately, although effective, this class of medications is potentially associated with psychiatric adverse effects that limit their utility. ${ }^{29}$ Furthermore, ergot DAs may determine severe valvular heart disease ${ }^{30}$ and accordingly their use has been essentially discontinued in medical practice. ${ }^{21}$ In addition to dopaminergic drugs, other nondopaminergic drugs including the $N$-methyl-d-aspartate receptor antagonist amantadine ${ }^{31,32}$ and the monoamine oxidase type B (MAO-B) inhibitors, ${ }^{33}$ rasagiline and selegiline, are capable of affording satisfactory symptomatic relief in the early phases of anti-PD therapy. While amantadine, given in adjunct to levodopa, has been used in lowering dyskinesia scores and improving motor complications in patients with $\mathrm{PD}$, the main use of MAO-B inhibitors has focused on their potential neuroprotective activity aimed at slowing down the course of the disease and preventing the onset of motor complications, with a demonstrated "disease-modifying" action in the case of rasagiline. ${ }^{34,35}$

In addition to conventional levodopa formulations with DDCI, controlled-release (CR) levodopa formulations (levodopa/carbidopa, Sinemet CR; levodopa/benserazide, Madopar PR) have been developed in an attempt to maintain a more stable plasma levodopa profile, and therefore reduce fluctuations for some patients. In clinical practice, however, this approach often leads to intermittent reemergence of symptoms due to the pulsatile nature of levodopa delivery, with associated phenomena of delayed "on" time with erratic absorption, a factor featuring an unpredictable bioavailability when compared with immediate-release conventional levodopa.$^{36}$ In this scenario, conflicting results have been described in clinical trials with some studies reporting significant clinical advantages over standard preparations, while others report erratic absorption and lack of additional therapeutic benefits, ${ }^{37-39}$ although CR-levodopa/ carbidopa may contribute towards alleviating disruptive nighttime symptoms. ${ }^{21}$

Furthermore, over the last few years, an innovative addition to the treatment options available has been provided by catechol-O-methyltransferase (COMT) inhibitors, which prevalently block the peripheral metabolism of levodopa to 3-0-methyldopa (3-OMD), reducing formation of 3-OMD and resulting in a measurable increase in the amount of levodopa entering the brain (Figure 1).

\section{Rationale for treatment with COMT inhibitors, entacapone, and tolcapone}

While the first COMT inhibitors described in the $1960 \mathrm{~s}^{40}$ were unselective, nonpotent, and considerably toxic, the 2 currently marketed COMT-inhibitors, entacapone $\left(\right.$ Comtan $\left.^{\circledR}\right)$, the only peripheral-acting compound, and the central-acting tolcapone $\left(\right.$ Tasmar $\left.^{\circledR}\right)$, are new potent, selective, and reversible nitrocatechol-type COMT inhibitors. ${ }^{41}$

Therefore, these agents, given adjunctively with levodopa/ DDCI, decrease levodopa turnover and increase its half-life, improving the area under the concentration (AUC) timecurve and delivery of levodopa to the brain. Moreover, these compounds reduce the frequency of both dose and administration of levodopa, decreasing "off" time and increasing "on" time which together result in an improved, prolonged clinical response to levodopa. ${ }^{42,43}$ For these reasons, the introduction of a COMT inhibitor combines with the rapid onset of levodopa to ensure protracted efficacy, an association theoretically providing a more continuous stimulation of dopamine receptors with reduced risk of motor complications. ${ }^{44}$ These advantages can be obtained simply by peripheral COMT inhibition.

Although more potent than entacapone, the COMT inhibitor tolcapone is not a first-line drug, as it requires strict monitoring due to potential hepatotoxicity. Indeed, in the past, descriptions of acute, fatal fulminant hepatitis, and potentially 
fatal neurological reactions, such as neuroleptic malignant syndrome and rhabdomyolysis, associated with tolcapone led to the withdrawal of its marketing authorization throughout the European community. The safety and tolerability of adjunctive tolcapone started concomitant to levodopa have recently been evaluated, with particular focus on changes in liver transaminase and potential hepatotoxicity; ${ }^{45}$ therefore, the use of tolcapone in the European community is currently restricted to patients who do not respond adequately to other therapies.

Conversely, among COMT inhibitors, entacapone represents the drug of choice in view of its satisfactory safety and tolerability profile. Due to its short half-life, however, entacapone requires frequent administrations, ${ }^{44}$ and a dose of $200 \mathrm{mg}$ entacapone at each levodopa and DDCI administration, up to 8 times per day, has been selected for clinical use mainly based on the results of a dose-response study. $^{21,46}$ In 2003, the US Food and Drug Administration (FDA) approved combined carbidopa, levodopa, and entacapone in a single tablet, with the brand name of Stalevo ${ }^{\circledR}$, for end-of-dose wearing-off. In a randomized, crossover study of 132 healthy subjects, the levodopa AUC was essentially the same when used in the triple combination vs single administration, indicating equivalent pharmacokinetics. ${ }^{47,48}$

\section{Use of entacapone in PD}

The first trials to evaluate the use of entacapone in patients with PD were 2 multicenter, double-blind, randomized, placebo-controlled 6-month studies conducted in North America ${ }^{49}$ and in the European Nordic countries. ${ }^{50}$ The studies were undertaken with the aim of demonstrating the clinical efficacy, safety, and tolerability of entacapone combined with levodopa in the treatment of parkinsonian patients with an end-of-dose deterioration in response to levodopa ("the wearing-off" phenomenon). In these studies, entacapone $200 \mathrm{mg}$ was administered in addition to each dose of levodopa/carbidopa or levodopa/benserazide, and both trials showed that entacapone was effective as an adjunct to levodopa. The duration of daily "on" time was increased by 1-1.2 hours and correspondingly the "off" times were decreased in patients with fluctuating PD. The effect of entacapone was more pronounced after the first dose, with drug benefits increasing throughout the day. ${ }^{49}$ Other end points in these pivotal trials indicated that entacapone with levodopa/ DDCI significantly improved total activities of daily living (ADL) and motor function scores. In line with its effect on levodopa pharmacokinetics, entacapone led to a reduction in daily levodopa dosages, which were lowered from baseline by $11 \%-16 \%$ in patients with entacapone and levodopa/ DDCI, compared with those receiving levodopa/DDCI alone. The beneficial effect was lost on withdrawal of entacapone. Entacapone was well tolerated. Adverse events with entacapone included diarrhea, urine discoloration, confusion, orthostatic hypotension, and increased dyskinesias, at times requiring a reduction in daily levodopa dosage.

Data concerning the efficacy and tolerability of entacapone over a 3-year period in PD patients were confirmed in a subsequent study. ${ }^{51}$ Moreover, further studies demonstrated that entacapone was well tolerated, providing additional antiparkinsonian benefits to levodopa therapy and in levodopa-treated PD patients experiencing wearing-off motor fluctuations despite adjunct DA therapy, ${ }^{52}$ and enhancing the pharmacokinetic and clinical response to CR levodopa formulations. ${ }^{53}$ Subsequently, further studies not only confirmed the finding of the excellent risk/benefit ratio seen in phase 3 controlled studies in daily neurological practice but also suggested that, independent of dosing frequency, the benefits of levodopa/DDCI therapy with entacapone were associated with a significant impact on patient quality of life, providing clinically relevant improvements in global status and quality of life in PD patients experiencing wearing-off on their current levodopa dosing frequency. ${ }^{54-56}$

Although only fluctuating patients were recruited in the earlier clinical studies, the efficacy of entacapone in patients with stable treated PD devoid of motor fluctuations had also been assessed in trials such as the Celomen study, with the aim of obtaining more experience on the use of entacapone in patients with less advanced disease.$^{57}$ This 6-month, randomized, placebo-controlled, double-blind study conducted at centers throughout Germany and Austria showed how the addition of entacapone to levodopa and carbidopa in the subset of PD patients without clear motor fluctuations modestly improved motor and ADL scores (respectively improving ADL scores from 11.3 to 10.3 , and motor scores from 28.0 to 25.7) and allowed a reduction in levodopa by $24 \pm 75 \mathrm{mg}$ in the entacapone group compared with an increase of $2 \pm 75 \mathrm{mg}$ with placebo.

However, despite the observation of a beneficial trend in nonfluctuating patients treated with entacapone, the differences between the groups were not statistically significant due to small sample size (25 patients for entacapone and 16 for placebo). An additional study performed at 29 sites in the United Kingdom and the Republic of Ireland, confirming the ability of entacapone to provide additional benefits to levodopa treatment in increasing "on" time in fluctuating PD patients, suggesting that the benefits afforded by combining 
levodopa with entacapone could be extended to patients who were not experiencing motor fluctuations, as evidenced by improved ADL scores and a relatively reduced levodopa requirement. ${ }^{58}$

To this regard, however, a subsequent double-blind, placebo-controlled, multicenter study of 750 patients taking levodopa and carbidopa without motor fluctuations demonstrated no improvement in Unified Parkinson's Disease Rating Scale (UPDRS) motor or ADL scores during entacapone, ${ }^{59}$ although several quality of life scales, as well as investigator and subject Clinical Global Assessment scores, indicated a considerable improvement.

\section{Use of combined carbidopal levodopa/entacapone (Stalevo $($ ) in PD}

In June 2003, the FDA approved triple combination tablets (Stalevo; Novartis) containing carbidopa, levodopa, and entacapone for the treatment of patients with idiopathic PD experiencing signs and symptoms of end-of-dose "wearingoff." In a randomized, crossover study of 132 healthy subjects, the levodopa AUC was essentially the same when used in the triple combination versus single administration, indicating equivalent pharmacokinetics. ${ }^{47,48}$

These data were confirmed by a randomized, parallelgroup, multinational European clinical trial investigating the use of Stalevo in the treatment of PD. ${ }^{60}$ This study found that Stalevo was well tolerated by patients diagnosed with idiopathic PD experiencing motor fluctuations, providing similar clinical improvements to those obtained with 2 separate tablets (ie, levodopa/DDCI and entacapone). Furthermore, the majority of PD patients included in this trial stated that they preferred treatment with Stalevo compared with taking separate levodopa/DDCI and entacapone, resulting in a better quality of life for patients than adjunct entacapone.

In this regard, an open-label study in PD patients experiencing wearing-off assessed the impact of switching from traditional levodopa/DDCI therapies with adjunctive entacapone therapy to Stalevo, revealing how the majority of patients treated with levodopa/DDCI plus entacapone can be easily and successfully switched to Stalevo. ${ }^{61}$ This observation has been confirmed by a more recent multicenter, open-label, 6-week study, ${ }^{62}$ based on the patient- and investigator-assessed Clinical Global Impression of Change (CGI), change from baseline UPDRS, motor/nonmotor wearing-off symptoms, and quality of life-visual analog scale, suggesting that switching from levodopa/carbidopa to Stalevo provided a significant benefit in PD patients with wearing-off.
A further trial, the FIRST-STEP study, was designed to demonstrate the enhanced efficacy provided by the added component. ${ }^{63}$ This 39-week, randomized, double-blind, multicenter trial, compared the efficacy and tolerability of the currently available triple combination tablets (Stalevo) containing carbidopa, levodopa, and entacapone with immediate-release levodopa/carbidopa in patients with early PD. This study additionally aimed to demonstrate that Stalevo was safe in early PD patients with a need for levodopa therapy. Results of this trial confirmed the greater symptomatic benefit provided by the use of Stalevo compared with levodopa/ carbidopa alone, demonstrating a significant difference in total UPDRS observed after 4 weeks, which was maintained throughout the 39-week observation period, with the greatest difference occurring at week 26 , without concomitant increase of the development of motor complications. Moreover, interestingly, the subjects' CGI scores were significantly improved in the Stalevo compared with the levodopa/carbidopa alone cohort, although the investigator CGI remained unchanged. However, two important limitations should be taken in account in evaluating these results. First, changes in Hoehn-Yahr, UPDRS motor scores, PDQ-39, and PDQ-8 scores did not differ significantly across groups. As expressed by the same authors, these data might potentially reflect a relative insensitivity to change of these measures in early $\mathrm{PD}$, together with the fact that the study was not powered to evaluate these measures, indicating that subjects are better able to recall their baseline status and provide a more accurate assessment of change than the investigator. ${ }^{63}$ The second limitation in the design of this study, as suggested by Müller, ${ }^{64}$ was the lack of comparisons with placebo and treatment with DAs.

In view of the concept that avoidance of troughs in plasma concentration of levodopa and more continuous nigrostriatal postsynaptic dopaminergic receptor stimulation could delay the occurrence and lead to a lower incidence of motor complications in PD patients, some trials ${ }^{65-70}$ were addressed to evaluate whether therapy with levodopa/ carbidopa/entacapone was more effective compared with standard levodopa/DDCI in reducing the onset of motor fluctuations when used from the beginning. This observation was postulated on theoretical grounds and from experimental research in animal models. A previous double-blind study with CR levodopa demonstrated how this formulation did not avoid low plasma levodopa trough levels and provided no continuous nigrostriatal postsynaptic dopaminergic receptor stimulation, mainly due to its erratic absorption. ${ }^{71}$ On the contrary, as previously cited, entacapone provides for 
more stable plasma levodopa levels with tonic stimulation of dopamine receptors in the striatum and, thus, might decrease the risk of developing motor complications.

On the basis of the observations outlined here, post hoc analyses of pooled data from 3 randomized, double-blind, clinical trials and open-label extensions ${ }^{49,50,57}$ in PD patients with motor complications were performed to determine whether early enhancement of levodopa therapy could lead to better long-term outcomes than delayed entacapone treatment. ${ }^{72}$ Although this study was limited by the lack of important outcome records, final data obtained suggested that early rather than delayed addition of entacapone to levodopa/DDCI in PD patients with wearing-off provided a modest clinical benefit over levodopa/DDCI maintained for up to 5 years. In this context, a further confirmatory trial (the STalevo Reduction in Dyskinesia Evaluation [STRIDEPD] study) was designed with the aim of demonstrating that levodopa/carbidopa/entacapone, when used as initial levodopa therapy, significantly delayed the time to onset of dyskinesia compared with the conventional levodopa/ carbidopa formulation. Unfortunately, the STRIDE-PD trial failed to prove the benefit of continuous dopaminergic stimulation with triple therapy in clinical settings. ${ }^{73}$

Recently, studies describing the effects of combined COMT inhibition with levodopa administration in reducing homocysteine synthesis have been published. In this regard, clear evidence has been provided implicating homocysteine as a risk factor for vascular diseases, cognitive impairment, and dementia. It is an acknowledged fact that cerebrovascular diseases and cognitive impairment worsen the prognosis of PD patients. Increased homocysteine in plasma has been reported in PD patients treated with levodopa applied only with a DDCI. ${ }^{74}$ This finding supports the onset of atherothrombotic disease in PD patients, as reported by epidemiological studies. ${ }^{75,76}$ Several works have discussed the potential benefits of peripheral COMT inhibition afforded by entacapone as adjunct to levodopa/DDCI in reducing plasma homocysteine levels. Although this hypothesis was not confirmed by several trials, ${ }^{77,78}$ other observations have demonstrated how treatment with levodopa/carbidopa/entacapone lowers homocysteine generation, reducing O-methylation of levodopa. In turn, the latter effects may positively influence the homocysteine-related progression of $\mathrm{PD},{ }^{74,79-81}$ while concomitantly decreasing the risk of cerebrovascular disease and cognitive impairment in parkinsonian patients.

\section{Disclosure}

The authors report no conflicts of interest in this work.

\section{References}

1. Gelb DJ, Oliver E, Gilman S. Diagnostic criteria for Parkinson disease. Arch Neurol. 1999;56(1):33-39.

2. de Lau LML, Breteler MMB. Epidemiology of Parkinson's disease. Lancet Neurol. 2006;5(6):525-535.

3. Nussbaum RL, Ellis CE. Alzheimer's disease and Parkinson's disease. N Engl J Med. 2003;348(14):1356-1364.

4. Müller T. Levodopa/carbidopa and entacapone in the treatment of Parkinson's disease: efficacy, safety, and patient preference. Patient Preference and Adherence. 2009;3:51-59.

5. Olanow CW, Watts RL, Koller WC. An algorithm (decision tree) for the management of Parkinson disease. Neurology. 2001;56(11 Suppl 5): $\mathrm{S} 1-\mathrm{S} 88$.

6. Jancovic J, Stacy M. Medical management of levodopa-associated motor complications in patients with Parkinson's Disease. CNS Drugs. 2007; 21(8):677-692.

7. Marsden CD, Parkes JD. Success and problems of long-term levodopa therapy in Parkinson's disease. Lancet. 1977;1(8007):345-349.

8. van Laar T. Levodopa-induced response fluctuations in patients with Parkinson's disease: strategies for management. CNS Drugs. 2003;17: 475-489.

9. Hauser RA, McDermott MP, Messing S. Factors associated with the development of motor fluctuations and dyskinesias in Parkinson Disease. Arch Neurol. 2006;63:1756-1760.

10. Obeso JA, Rodriguez-Oroz MC, Chana P, Lera G, Rodriguez M, Olanow CW. The evolution and origin of motor complications in Parkinson's disease. Neurology. 2000;55 Suppl 4:S13-S20; discussion $\mathrm{S} 21-\mathrm{S} 23$.

11. Obeso JA, Rodriguez-Oroz M, Marin C, et al. The origin of motor fluctuations in Parkinson's disease: importance of dopaminergic innervation and basal ganglia circuits. Neurology. 2004;62 Suppl 1:S17-S30.

12. Olanow CW. Movement disorders: a step in the right direction. Lancet Neurol. 2006;5:3-5.

13. Dewey RB Jr. Management of motor complications in Parkinson's disease. Neurology. 2004;62 Suppl 4:S3-S7.

14. Riederer P, Gerlach M, Müller T, Reichmann H. Relating mode of action to clinical practice: dopaminergic agents in Parkinson's disease. Parkinsonism Relat Disord. 2007;13(8):466-479.

15. Jankovic J. Parkinson's disease therapy: tailoring choices for early and late disease, young and old patients. Clin Neuropharmacol. 2000;23: 252-261.

16. Bergamasco B, Frattola L, Muratorio A, Piccoli F, Mailland F, Parnetti L. Alpha-dihydroergocryptine in the treatment of de novo parkinsonian patients: results of a multicentre, randomized, double-blind, placebo-controlled study. Acta Neurol Scand. 2000;101:372-380.

17. Barone P, Bravi D, Bermejo-Pareja F, et al; for Pergolide Monotherapy Study Group. Pergolide monotherapy in the treatment of early PD: a randomized, controlled study. Neurology. 1999;53:573-579.

18. Shannon KM, Bennett JP Jr, Friedman JH, for Pramipexole Study Group. Efficacy of pramipexole, a novel dopamine agonist, as monotherapy in mild to moderate Parkinson's disease. Neurology. 1997;49: 724-728.

19. Adler CH, Sethi DK, Hauser RA, et al. Ropinirole for the treatment of early Parkinson's disease. Neurology. 1997;49:393-399.

20. Giladi N, Boroojerdi B, Korczyn AD, Burn DJ, Clarke CE, Schapira AH; SP513 investigators. Rotigotine transdermal patch in early Parkinson's disease: a randomized, double-blind, controlled study versus placebo and ropinirole. Mov Disord. 2007;22(16):2398-2404.

21. Jankovic J, Aguilar LG. Current approaches to the treatment of Parkinson's disease. Neuropsychiatr Dis Treat. 2008;4:743-757.

22. Oertel WH, Wolters E, Sampaio C, et al. Pergolide versus levodopa monotherapy in early Parkinson's disease patients: the PELMOPET study. Mov Disord. 2005;21:343-353.

23. Bracco F, Battaglia A, Chouza C, et al. The long-acting dopamine receptor agonist cabergoline in early Parkinson's disease: final results of a 5-year, double-blind, levodopa-controlled study. CNS Drugs. 2004; 18:733-746. 
24. Parkinson Study Group. Pramipexole vs levodopa as initial treatment for Parkinson disease: a randomized controlled trial. JAMA. 2000;284: 1931-1938.

25. Holloway RG, Shoulson I, Fahn S, et al. Pramipexole vs levodopa as initial treatment for Parkinson disease: a 4-year randomized controlled trial. Arch Neurol. 2004;61:1044-1053.

26. Rascol O, Brooks DJ, Korczyn AD, De Deyn PP, Clarke CE, Lang AE, for 056 Study Group. A five-year study of the incidence of dyskinesia in patients with early Parkinson's disease who were treated with ropinirole or levodopa. N Engl J Med. 2000;342:1484-1491.

27. Whone AL, Remy P, Davis MR, et al. The REAL-PET study: slower progression in early Parkinson's disease treated with ropinirole compared with levodopa. Neurology. 2002;58 Suppl 3:A82-A83.

28. Parkinson Study Group. Dopamine transporter brain imaging to assess the effects of pramipexole vs levodopa on Parkinson disease progression. JAMA. 2002;287:1653-1661.

29. Voon V, Pessiglione M, Brezing C, et al. Mechanisms underlying dopamine-mediated reward bias in compulsive behaviors. Neuron. 2010;65(1):135-142.

30. Zanettini R, Antonini A, Gatto G, Gentile R, Tesei S, Pezzoli G. Valvular heart disease and the use of dopamine agonists for Parkinson's disease. N Engl J Med. 2007;356(1):39-46.

31. Luginger E, Wenning GK, Bosch S, Poewe W. Beneficial effects of amantadine on L-dopa-induced dyskinesias in Parkinson's disease. Mov Disord. 2000;15(5):873-878.

32. Snow BJ, Macdonald L, Mcauley D, Wallis W. The effect of amantadine on levodopa-induced dyskinesias in Parkinson's disease: a double-blind, placebo-controlled study. Clin Neuropharmacol. 2000;23(2):82-85.

33. Henchcliffe C, Schumacher HC, Burgut FT. Recent advances in Parkinson's disease therapy: use of monoamine oxidase inhibitors. Expert Rev Neurother. 2005;5(6):811-821.

34. Palhagen S, Heinonen E, Hagglund J, et al. Selegiline slows the progression of the symptoms of Parkinson disease. Neurology. 2006;66 1200-1206.

35. Olanow CW, Rascol O, Hauser R, et al; ADAGIO Study Investigators. A double-blind, delayed-start trial of rasagiline in Parkinson's disease. N Engl J Med. 2009;361(13):1268-1278.

36. Stocchi F. The levodopa wearing-off phenomenon in Parkinson's disease: pharmacokinetic considerations. Expert Opin Pharmacother. 2006; 7:1399-1407.

37. Pahwa R, Busenbark K, Huber SJ, Michalek D, Hubble JP, Koller WC. Clinical experience with controlled-release carbidopa/levodopa in Parkinson's disease. Neurology. 1993;43:677-681.

38. Koller WC, Pahwa R. Treating motor fluctuations with controlled-release levodopa preparations. Neurology. 1994;44 Supp1 6:S23-S28.

39. Koller WC, Hutton JT, Tolosa E, Capilldeo R. Immediate-release and controlled-release carbidopa/levodopa in PD: a five year randomized multicenter study. Carbidopa/Levodopa Study Group. Neurology. 1999; 53(5):1012-1019.

40. Guldberg HC, Marsden CA. Catechol-O-methyl transferase: pharmacological aspects and physiological role. Pharmacol Rev. 1975;27:135-206.

41. Kaakkola S. Clinical pharmacology, therapeutic use and potential of COMT inhibitors in Parkinson's disease. Drugs. 2000;59(6):1233-1250

42. Müller T. Tolcapone in the management of Parkinson's disease. Aging Health. 2006;2(5):709-720.

43. Ruottinen HM, Rinne UK. COMT inhibition in the treatment of Parkinson's disease. J Neurol. 1998;245(11 Suppl 3):25-34.

44. Schrag A. Entacapone in the treatment of Parkinson's disease. Lancet Neurol. 2005;4:366-370.

45. Lees AJ, Ratziu V, Tolosa E, Oertel WH. Safety and tolerability of adjunctive tolcapone treatment in patients with early Parkinson's disease. J Neurol Neurosurg Psichiatry. 2007;78(9):944-948.

46. Ruottinen HM, Rinne UK. A double-blind pharmacokinetic and clinical dose-response study of entacapone as an adjuvant to levodopa therapy in advanced Parkinson's disease. Clin Neuropharmacol. 1996;19: 283-296.
47. Heikkinen H, Varhe A, Lyly V, et al. New levodopa. carbidopa and entcapone combination tablets. European J Neurology. 2003;10:164.

48. Hauser RA. Levodopa/carbidopa/entacapone (Stalevo). Neurology. 2004;62:64-71.

49. Parkinson Study Group. Entacapone improves motor fluctuations in levodopatreated Parkinson's disease patients. Ann Neurol. 1997;42:747-755.

50. Rinne UK, Larsen JP, Siden A, Worm-Peterson J. Entacapone enhances the response to levodopa in parkinsonian patients with motor fluctuations. Neurology. 1998;51:186-189.

51. Larsen JP, Worm-Petersen J, Siden A, Gordin A, Reinikainen K, Leinonen M. The tolerability and efficacy of entacapone over 3 years in patients with Parkinson's disease. Eur J Neurol. 2003;10:137-146.

52. Fenelon G, Gimenez-Roldan S, Montastruc JL, et al. Efficacy and tolerability of entacapone in patients with Parkinson's disease treated with levodopa plus a dopamine agonist and experiencing wearing-off motor fluctuations: a randomized, double-blind, multicentre study. J Neural Transm. 2003;110:239-251.

53. Piccini P, Brooks DJ, Korpela K, Pavese N, Karlsson M, Gordin A. The catechol-O-methyltransferase (catechol-O-methyltransferase) inhibitor entacapone enhances the pharmacokinetic and clinical response to Sinemet CR in Parkinson's disease. J Neurol Neurosurg Psychiatry. 2000;68:589-594.

54. Durif F, Devaux I, Pere JJ, Delumeau JC, Bourdeix I. Efficacy and tolerability of entacapone as adjunctive therapy to levodopa in patients with Parkinson's disease and end-of-dose deterioration in daily medical practice: an open, multicenter study. Eur Neurol. 2001;45:111-118.

55. Onofrj M, Thomas A, Vingerhoets F, et al. Combining entacapone with levodopa/DDCI improves clinical status and quality of life in Parkinson's Disease (PD) patients experiencing wearing-off, regardless of the dosing frequency: results of a large multicentre open-label study. J Neural Transm. 2004;111(8):1053-1063.

56. Reichmann H, Boas J, Macmahon D, Myllyla V, Hakala A, Reinikainen K. Efficacy of combining levodopa with entacapone on quality of life and activities of daily living in patients experiencing wearing-off type fluctuations. Acta Neurol Scand. 2005;111:21-28.

57. Poewe WH, Deuschl G, Gordin A, Kultalahti ER, Leinonen M. Efficacy and safety of entacapone in Parkinson's disease patients with suboptimal levodopa response: a 6-month randomized placebo-controlled doubleblind study in Germany and Austria (Celomen study). Acta Neurol Scand. 2002;105:245-255.

58. Brooks DJ, Sagar H. Entacapone is beneficial in both fluctuating and non-fluctuating patients with Parkinson's disease: a randomised, placebo controlled, double blind, six month study. J Neurol Neurosurg Psychiatry. 2003;74:1071-1079.

59. Olanow CW, Kieburtz K, Stern M, et al. Double-blind, placebocontrolled study of entacapone in levodopa-treated patients with stable Parkinson disease. Arch Neurol. 2004;61:1563-1568.

60. Brooks DJ, Agid Y, Eggert K, Widner H, Ostergaard K, Holopainen A; TC-INIT Study Group. Treatment of end-of-dose wearing-off in parkinson's disease: stalevo (levodopa/carbidopa/entacapone) and levodopa/DDCI given in combination with Comtess/Comtan (entacapone) provide equivalent improvements in symptom control superior to that of traditional levodopa/DDCI treatment. Eur Neurol. 2005; 53(4):197-202.

61. Myllylä V, Haapaniemi T, Kaakkola S, et al. Patient satisfaction with switching to Stalevo: an open-label evaluation in PD patients experiencing wearing-off (Simcom Study). Acta Neurol Scand. 2006; 114(3):181-186.

62. Eggert K, Skogar O, Amar K, et al. Direct switch from levodopa/ benserazide or levodopa/carbidopa to levodopa/carbidopa/entacapone in Parkinson's disease patients with wearing-off: efficacy, safety and feasibility - an open-label, 6-week study. J Neural Transm. 2010; 117(3):333-342.

63. Hauser RA, Panisset M, Abbruzzese G, Mancione L, Dronamraju N, Kakarieka A; FIRST-STEP Study Group. Double-blind trial of levodopa/ carbidopa/entacapone versus levodopa/carbidopa in early Parkinson's disease. Mov Disord. 2009;24(4):541-550. 
64. Müller T, Muhlack S. Peripheral COMT inhibition prevents levodopa associated homocysteine increase. J Neural Transm. 2009;116(10): 1253-1256.

65. Marin C, Aguilar E, Bonastre M, Tolosa E, Obeso JA. Early administration of entacapone prevents levodopa-induced motor fluctuations in hemiparkinsonian rats. Exp Neuro. 2005;192:184-193.

66. Hadj TA, Gregoire L, Bangassoro E, Bedard PJ. Sustained cabergoline treatment reverses levodopa-induced dyskinesias in parkinsonian monkeys. Clin Neuropharmacol. 2000;23:195-202.

67. Olanow W, Schapira AH, Rascol O. Continuous dopamine-receptor stimulation in early Parkinson's disease. Trends Neurosci. 2000;23: S117-S126.

68. Jenner P. Avoidance of dyskinesia: preclinical evidence for continuous dopaminergic stimulation. Neurolog. 2004;62:S47-S55.

69. Pearce RK, Banerji T, Jenner P, Marsden CD. De novo administration of ropinirole and bromocriptine induces less dyskinesia than L-dopa in the MPTP-treated marmoset. Mov Disord. 1998;13:234-241.

70. Maratos EC, Jackson MJ, Pearce RK, Jenner P. Antiparkinsonian activity and dyskinesia risk of ropinirole and L-DOPA combination therapy in drug naive MPTP-lesioned common marmosets (Callithrix jacchus). Mov Disord. 2001;16:631-641.

71. Koller WC, Hutton JT, Tolosa E, Capilldeo R: Immediate-release and controlled-release carbidopa/levodopa in PD: a 5-year randomized multicenter study. Carbidopa/Levodopa Study Group. Neurology. 1999; 53:1012-1019.

72. Nissinen H, Kuoppamä M, Leinonen M, Schapira AH. Early versus delayed initiation of entacapone in levodopa-treated patients with Parkinson_s disease: a long-term, retrospective analysis. Eur J Neurol. 2009;16:1305-1311.
73. Kliveny P, Vecsei L. Novel therapeutic strategies in Parkinson's disease. Eur J Clin Pharmacol. 2010;66:119-125.

74. Müller T. Role of homocysteine in the treatment of Parkinson's disease. Expert Rev Neurother. 2008;8(6):957-967.

75. Ben Shlomo Y, Marmot MG. Survival and cause of death in a cohort of patients with parkinsonism: possible clues to aetiology? J Neurol Neurosurg Psychiatry. 1995;58(3):293-299.

76. Gorell JM, Johnson CC, Rybicki BA. Parkinson's disease and its comorbid disorders: an analysis of Michigan mortality data, 1970 to 1990. Neurology. 1994;44(10):1865-1868.

77. Postuma RB, Espay AJ, Zadikoff C, et al. Vitamins and entacapone in levodopa-induced hyperhomocysteinemia: a randomized controlled study. Neurology. 2006;66(12):1941-1943.

78. Nevrly M, Kanovsky P, Vranova H, Langova K, Hlustik P. Effect of levodopa and entacapone treatment on plasma homocysteine levels in Parkinson's disease patients. Parkinsonism Relat Disord. 2009;15(6): $477-478$.

79. de Bonis ML, Tessitore A, Pellecchia MT, et al. Impaired transmethylation potential in Parkinson's disease patients treated with L-dopa. Neurosci Lett. 2010;468(3):287-291.

80. Valkovic P, Benetin J, Blazacek P, Valkovicova L, Gmitterova K, Kukumberg P. Reduced plasma homocysteine levels in levodopa/ entacapone treated Parkinson patients. Parkinsonism Relat Disord. 2005;11:253-256.

81. Zoccolella S, Lamberti P, Armenise E, et al. Plasma homocysteine levels in Parkinson's disease: role of antiparkinsonian medications. Parkinsonism Relat Disord. 2005;11:131-133.
Neuropsychiatric Disease and Treatment

\section{Publish your work in this journal}

Neuropsychiatric Disease and Treatment is an international, peerreviewed journal of clinical therapeutics and pharmacology focusing on concise rapid reporting of clinical or pre-clinical studies on a range of neuropsychiatric and neurological disorders. This journal is indexed on PubMed Central, the 'PsycINFO' database and CAS, and is the official

\section{Dovepress}

journal of The International Neuropsychiatric Association (INA). The manuscript management system is completely online and includes a very quick and fair peer-review system, which is all easy to use. Visit http://www.dovepress.com/testimonials.php to read real quotes from published authors. 